\title{
Derived Nouns in Austen's Novel Sense and Sensibility
}

\author{
Ni Putu Diah Sri Lestari \\ English Department - Faculty of Arts - Udayana University \\ Denpasar, Bali, Indonesia \\ Email: putudiah074@gmail.com
}

\begin{abstract}
This study is entitled Derived Nouns in Austen's Novel Sense and Sensibility. This study aims to identify kinds of derivational suffixes nouns found in Derived Nouns in Austen's novel Sense and Sensibility and to explain meanings of the derived nouns. The data were taken from Austen's novel Sense and Sensibility published in 1811. This study used library research and applied documentation method to collect the data. The method used in data analysis was the qualitative method. The technique of presenting data used the descriptive method for identifying the process of the derivational forming noun. This study applied the kinds of derived suffixes nouns proposed by McCarthy (2002) as the main theory, and meaning of derived nouns proposed by Haspelmath and Sims (2010) as the supporting theory. The findings showed that there were three classes; they are: suffixes forming nouns from nouns such as the suffixes -er, -ship and -hood, suffixes forming adjectives from nouns are the suffixes -ity, -ness, and -ism, and suffixes forming verb from nouns are the suffixes -ance, ence, -ment, -ing, -((a)t)ion, and -al. The derivational meanings denoted deverbal nouns found in the data such as agent nouns and action nouns. The derivational meanings denoted deadjective nouns were quality nouns. On the other side, the derivational meanings denoted by denominal nouns were status nouns.
\end{abstract}

Keywords: Derivational, Suffixes, Derived noun.

\section{INTRODUCTION}

Morphology is a branch of Micro Linguistics. Morphology is a study about morphemes and how to combine morphemes to be a word. In morphology, we can learn the details of the structure of words, affixes, and analysis. Morphology is the identification, analysis, and description of the structure of given language morphemes and other linguistic units, such as root words, affixes, parts of speech, intonation/stress, or implied context (words in a lexicon are the subject matter of lexicology). (Oxford Advanced Learner's Dictionary of Current English).

Morphology can be divided into two main branches, such as inflectional morphology and derivational morphology. According to Srijono (2010:51), "Affixation is a morphological process in which an affix or affixes are added to one or more free morpheme". According to Katamba (1993:45), "Base is any unit whatsoever to which affixes of any kind can be added. The affixes attached to a base may be inflectional affixes selected for syntactic reasons or derivational affixes which alter the meaning or grammatical category of the base". Affixes are divided into three types: prefixes, infixes, and suffixes.
The derivation is the morphological process in derivational affix attached to a base form to create a new word. Affixes are bound morphemes, which cannot stand alone and must be attached to another morpheme or words. Affixes include prefixes, suffixes, and infixes. Prefixes are attached before a base, suffixes are attached after a base, and infixes are attached inside a base. The classification of the new word that is often called a derived word is formed by the suffixes which are added to the base word. When a suffix is added to a base word, it can create a new word that is derived from the base word but has a different meaning, called derivational suffixes.

Based on the phenomena mentioned above, this study focuses on describing the process Derived Nouns in Austen's novel Sense and Sensibility, which contains the search of the suffix in the novel is very interesting to find many English derivational. Therefore, this study was conducted to identify the kinds of nominal suffixes of words and the meanings of the derived nouns. The writer chose the topic of derivational because it is very important to identify the process, class changing, and meaning of a derived noun. 


\section{Problem of the Study}

Based on the background given above, some problems need to be discussed. The problems are formulated as follows:

a. What kinds of derivational suffixes and Derived Nouns are found in Austen's novel Sense and Sensibility?

b. What are the meanings of the derived nouns?

\section{Aims of the Study}

a. To identify kinds of derivational suffixes and Derived Nouns found in Austen's novel Sense and Sensibility.

b. To explain the meanings of the derived nouns.

\section{RESEARCH METHOD}

The morphology of this study is divided into four methods; they consist of: data source, method, and technique collecting data, method, and technique of analyzing data and method and technique of the presenting data.

\section{Data Source}

The primary data were taken from Austen's novel Sense and Sensibility published in 1811. The novel was adapted as the movie by the same name. The novel was used as the data source because there were many derivational processes found in this novel and indicated many derived words found so it is related to the topic of this study. The story tells about life and love stories of the Dashwood sisters, Elinor, and Marianne as they come of age. They have an older, stingy half-brother, John, and a younger sister, Margaret.

\section{Method and Technique of Collecting data}

Before doing the analysis, collecting the data needs to follow a certain procedure to obtain appropriate and sufficient data. This study is library research which applied the documentation method. The data in this study were collected from 39 in Austen's novel Sense and Sensibility. The data were collected through several numbers of steps, namely:

a. First, the object of this study was chosen. The novel has a large number of pages and was chosen because there were many derivational suffixes nouns.

b. Second, reading the novel to find words related to derivational suffixes nouns.

c. Third, taking note of words with the original sentences to find derivational suffixes noun.

d. Classification of the data based on the categories of derivational noun suffixes.

e. Finally, decreasing the similar words in each of the data.

\section{Method and Technique of Analyzing data}

The method used in data analysis is qualitative because the object of the research is to inform the words, not in number. There were several processes to analyze the data:

a. Identifying the suffixes taken from the novel based on the kinds of derived suffixes nouns proposed by McCarthy (2002)

b. Explaining the meaning of derived nouns based on the types of meaning proposed by Haspelmath and Sims (2010).

\section{Method and Technique of Presenting data}

In this research descriptive method was used to identify the process of derivational forming nouns found in Austen's novel Sense and Sensibility. First, the data were collected to make a process of derivational suffixes. Second, analyzing Austen's novel Sense and Sensibility and making an example. This study needs a description of the analysis, tree diagram, and tables. Finally, explaining the meaning of derived nouns based on the theory proposed by Haspelmath and Sims (2010).

\section{RESULT AND DISCUSSION}

\section{Kinds of Derivational Suffixes Forming Noun}

Suffixes forming nouns from nouns suffix -ship, -hood are nominal suffixes. Suffixes -ship, -hood belongs to 'the state of being $\mathrm{X}$ ', where $\mathrm{X}$ is the base nouns.

The following is the example of data in the use of the suffixes -ship, -hood found in the data sources:

a. .... the house itself was under the guardianship of the fir.... (1811: 264).

b. .... in the neighborhood of Norland; for to remove far from that beloved spot was impossible.... (1811: 13)

The underlined words lexemes of guardianship and neighborhood are the examples of words that get the attachments of the suffix -ship and hood.

The morphological tree diagram is as follows:

a. Guardianship

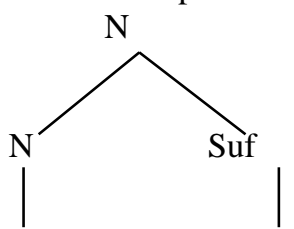

Guardian

$$
\text { -ship }
$$

b. Neighborhood

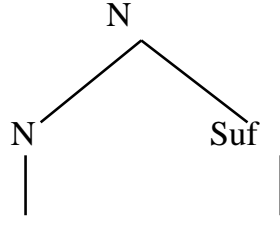

Neighbour -hood

From the picture above, the tree diagram shows that the attachment of the suffix -ship after the base 
word creates a new lexeme which belongs to the same word class of the base. In this case, the base is attached to the suffix -ship and -hood such as; guardian and neighbor. Then, after attaching the suffix -ship and -hood the base word changes into; guardianship and neighborhood. So, the meaning of the suffix -ship, according to McCharty (2002: 49), means that 'state of being an $\mathrm{X}$ ', where $\mathrm{X}$ is the base word.

The example of the process derivational suffix -ship and -hood is as follows:

Suffix forming nouns from adjectives of the suffix -ity functions to produce nouns.

The following is the example of the use of the suffix -ity found in the data sources:

a. .... I believe, to doubt the morality of my conduct in general, and was moreover discontented with the very little attention.... (1811:282)

The underlines lexeme of morality is the examples of words that can get the suffix -ity.

The morphological tree diagram is as follows:

a. Morality

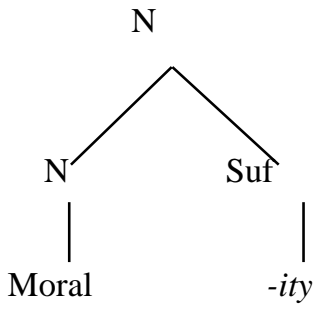

From the picture above, the tree diagram shows the attachment suffix -ity after the base word, creating a new lexeme belonging to the same word class of the base. In this case, the base is attached with the suffix -ity such as; moral. Then, after attaching the suffix -ity, the base word changes into morality. The derivational process alters the grammatical class of the base from an adjective into nouns. The meaning suffix -ity according to McCharty (2002: 49), is indicating the meaning 'property of being $\mathrm{X}$ '.

Suffix forming nouns from verbs of the suffix ance, (-ence) is attached to a verb to form abstract noun with the meaning 'activity or the result of $\mathrm{X}$-ing (base)', where $\mathrm{X}$ is the base verb.

The followings are the data of the use of the suffix ance, (-ence) found in the data source:

a. .... attended too with the assurance of her

expecting.... (1811: 185)

The underlined lexeme of assurance is the example of a word that can get the attachment of the suffix ance.

The morphological tree diagram is as follows:

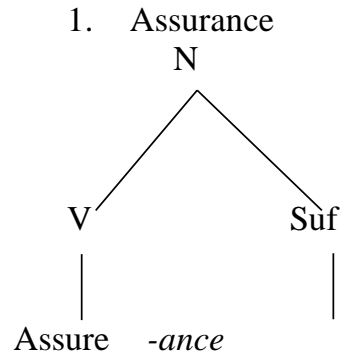

From the picture above, the tree diagram shows the attachment of the suffix -ance after the base word, creating a new lexeme which belongs to the same word class of the base. The base is from the verb such as assure. After attaching the suffix -ance, (-ence) it becomes assurance. The derivational process is a grammatical class of the base verb into a noun. The meaning of the suffix -ance, according to. McCharty (2002: 51), is 'activity or result of X-ing.

\section{Meaning of Derived Nouns}

\section{Deverbal nouns}

According to Haspelmath and Sims (2010: 87), the meaning of nouns derived from the verb class is agent noun, instrument noun, patient noun, action noun. Only patient noun, and instrument noun which was not found in the data source.

Agent noun is related to a noun denoting to the agent or participant of the action usually the attachment of suffix - er to the verb base.

Example:

a. ...by what painter Mr. Willoughby's portrait was drawn, and at what warehouse Miss Grey's clothes might be seen.... (1811: 190).

\begin{tabular}{llcc}
\hline No & Base & Suffix & Derived Nouns \\
\hline 1. & Paint & $-e r$ & Painter \\
\hline
\end{tabular}

The tree diagram in example 1: depicts that the word of Painter its derived noun. It can be divided into two parts; they are the word of Paint which is a verb and belongs to a base, later on, the suffix -er is attached to the side of the end painter. It becomes a painter which has the function as a stem. The word paint means that colored liquid is put on a surface. (Hornby, 2008: 315). However, the word painter means that person whose job is painting the walls of a building. (Hornby, 2008: 315). From the definition above, it can be concluded that the printer is an agent of the action paint.

\section{Deadjectival nouns}

The quality noun was concerned with the state or quality of being $X$. Example: 
a. .... my engagement by such acts of assistance and kindness to them as you have described.... (1811.12)

The tree diagram in example 1: kindness is a derived noun. It can be divided into two parts; they are the word of the kind which is adjective and belongs to a base, later on, the suffix -ness which is attached to the end, creating the word kindness. The word kind means that attitude of friendly and thoughtful to others (Hornby, 2008: 285). However, the word morality means that principles of good or right behavior (Hornby, 2008: 285). From the definition above, it can be concluded that kindness is a quality noun because the word kindness refers to the state or quality of being kind.

\section{Denominal noun}

A status noun is a denominal noun to denoting a state of being $X$.

a. .... she believed it to be no more than

friendship.... (1811: 21)

\begin{tabular}{llll}
\hline No & Base & Suffix & Derived Nouns \\
\hline 1. & Friend & -ship & Friendship \\
\hline
\end{tabular}

The tree diagram in example 1: friendship is a derived noun. It can be divided into two parts; they are the word of friend which is a noun and belongs to a base, later on, the suffix -ship which is attached to the end of the word, creating the word friendship. The word friend means that a person you know well and like, but who is not a relative, helper, or supporter, becoming a friend of somebody (Hornby, 2008: 285). Afterward, the word friendship means that friendly relationship (Hornby, 2008: 285). From the definition above, it can be concluded that friendship is the status noun because the word friendship refers to the state or quality of being a friend.

\section{CONCLUSION}

This study discussed Derived Nouns in Austen's Novel Sense and Sensibility, based on the theories proposed by McCharty (2002) and Haspelmath and Sims (2010). From the previous analysis in chapter III, the conclusion can is as follows:

The derivational suffixes of nouns found in Austen's Novel Sense and Sensibility belong to noun bases such as the suffixes -er, -ship and -hood, which belong to adjective bases such as suffixes -ity, -ness, and -ism, and the last which belongs to verb suffixes-ance, -ence, -ment, -ing, -((a)t)ion, and-al.

There are agent nouns and action nouns with the derivational meanings of deverbal nouns. The agent noun related to the agent or participant of the action is the suffix $-e r$. Besides, the action noun is related to the event or action itself such as suffix -ance, -ment, ing, ((a)t)ion, and al. Furthermore, there are quality nouns in derivational meanings of deadjectival nouns. A quality noun is related to the state or quality

\begin{tabular}{cccc}
\hline No & Base & Suffix & $\begin{array}{c}\text { Derived } \\
\text { Nouns }\end{array}$ \\
\hline 1. & Kind & -ness & Kindness \\
\hline
\end{tabular}

of being X (base) such as suffix -ity, -ness, -and ism. The last analysis discusses that in the data source diminutive noun, augmentative noun, inhabitant noun, and female noun were not found. The only status noun which was found in the derivational meaning of the denominal noun. The status noun is related to denoting a state of being $\mathrm{X}$ (base) such as suffix -ship and-hood.

\section{REFERENCES}

Austen, J. 1811. Sense and Sensibility. Wikisource

Haspelmath, M., and Sims, A. D. 2010.

UnderstandingMorphology.

London: Hodder Education.

Hornby, A.S. 2008. Oxford Advanced Learner's Dictionary of Current English (fifth ed.). Oxford University Press, New York.

Katamba, F. 1993. Morphology. The Macmillan Press: London.

Matthews, P.H. 1991. Morphology. Cambridge University Press: New York.

McCarthy, A.C. 2002. An Introduction of English Morphology. Great Britain: Edinburg University Press.

Srijono, D. 2010. An Introductory Course of Linguistics. Surakarta: Muhammadiyah University Press. 